\title{
O CLIMA URBANO COMO CONSTRUÇÃO SOCIAL NO CONTEXTO DA PRODUÇÁO DO ESPAÇO URBANO PERIFÉRICO DA ZONA LESTE DE SÃO PAULO ${ }^{1}$
}

\author{
THE URBAN CLIMATE AS A SOCIAL CONSTRUCTION IN THE \\ CONTEXT OF THE PRODUCTION OF THE PERIPHERAL URBAN \\ ENVIRONMENT IN THE EAST ZONE OF SÁO PAULO \\ EL CLIMA URBANO COMO UNA CONSTRUCCIÓN SOCIAL EN \\ EL CONTEXTO DE LA PRODUCCIÓN DE LAS ZONAS URBANAS \\ PERIFERICAS DEL ESTE DE SAO PAULO
}

\begin{abstract}
Fernando Rocha Reis
Bacharel e licenciado em Geografia pela FFLCH/USP fernandorochareis89@gmail.com / fernando.reis@usp.br
\end{abstract}

Emerson Galvani

Prof. Dr. do Departamento de Geografia da FFLCH/USP

egalvani@usp.br

\begin{abstract}
Resumo: O clima urbano como uma construção social é entendido a partir da inter -relação da sociedade com o espaço no processo de produção e reproduçáo desigual do espaço. Nas cidades brasileiras, marcadas pela desigualdade social, essa é uma característica marcante, ao ponto de deixar marcas na paisagem urbana através da segregação socioespacial e o uso diferenciado da cidade. Todos os fatores citados acabam refletindo no microclima dos diversos bairros e na cidade como um todo. $\mathrm{O}$ tipo de urbanizaçáo dos bairros de alto padrão é distinto do tipo dos bairros de baixo padrão, no que diz respeito à arborização, oferta de equipamentos urbanos, tamanho dos domicílios, material construtivo, dentre outras características. Nesse contexto que este artigo intitulado " $O$ clima urbano como construção social no contexto da produção do espaço urbano periférico da zona leste de Sáo Paulo" tem como objetivo mostrar como a produçáo desigual do espaço contribui para produção de microclimas diferentes. $\mathrm{O}$ estudo buscou compreender o processo de produção desigual do espaço, seus reflexos no clima urbano, entendido como uma construção social.
\end{abstract}

1 Esse artigo foi elaborado a partir dos resultados do TGI - Trabalho de Graduação Individual intitulado: O clima urbano como construção social no contexto da produção do espaço urbano periférico da zona leste de São Paulo - estudo microclimático do Parque Chico Mendes e seu entorno. 
Palavras-chave: clima urbano; produção do espaço; paisagem; microclima; segregaçáo socioespacial.

Abstract: The urban climate as a social construction is understood as the result of the interrelationship between society and environment in the process of unequal production and reproduction of the aforesaid environment. In Brazilian cities marred by social inequality —, this is a noticeable characteristic to leave traces in the urban landscape throug $h$ socio and spatial segregation and the differentiated utilization of a given city. In other words, the above-mentioned elements reflect not only on the microclimate of the diverse neighborhoods but also on the city. Thus, the type of urbanization of hig h standard neighborhoods differs from the one of low standard neighborhoods in terms of afforestation, offer of urban equipment, size of domiciles, building material, among other characteristics. In this sense, this paper - The urban climate as a social construction in the context of the production of the peripheral urban environment in the East zone of São Paulo - aims to illustrate how the unequal production of the environment culminates in the production of different microclimates. This study is also intended to interpret the process of unequal production of the urban environment, its consequences in the urban climate - seen as a social construction.

Key words: urban climate; production of the space; landscape; microclimate; spatial segregation.

Resumen: El clima urbano como construcción social es entendido a partir de la interrelación entre la sociedad y el espacio en el proceso de producción y reproducción desigual del espacio. En las ciudades brasileñas, marcadas por la desigualdad social, esta es una característica fundamental, al punto de dejar marcas en el paisaje urbano a través de la segregación socio-espacial y el uso diferencial de la ciudad. Todos los factores mencionados son reflejados en el microclima de los distintos barrios y la ciudad en su conjunto. Los barrios de lujo de la urbanización son diferentes a los barrios de bajos ingresos, con respecto a la forestación, la provisión de instalaciones urbanas, el tamaño de los hogares, material de construcción, entre otras características. En este contexto, este artículo titulado "El clima urbano como una construcción social en el contexto de la producción de las zonas urbanas periféricas del este de Sao Paulo" tiene como objetivo mostrar cómo la producción desigual del espacio contribuye a la producción de diferentes microclimas. El estudio tuvo como objetivo comprender el proceso de producción desigual del espacio y sus efectos sobre el clima urbano, entendidos como una construcción social.

Palabras clave: clima urbano; producción del espacio; paisaje; microclima; segregación socio-espacial. 


\section{INTRODUÇÃO}

As repercussóes do clima geradas pelo processo de (re)produçáo do espaço urbano têm implicaçóes sobre a superfície terrestre. O espaço urbano é produzido e apropriado de forma desigual, o que significa dizer que os efeitos do clima gerados pelo processo de produção do espaço urbano teráo consequências diferentes para as populaçóes com poder aquisitivo distinto e que vivem em bairros "diferenciados". Portanto, é necessário incorporar a dimensão social nos estudos de clima urbano, visto que a sociedade produz o espaço urbano.

Monteiro (1990) já sinalizava os reflexos da urbanização na alteração das condiçóes climáticas e a produção de um clima urbano, como pode ser observado na seguinte citação:

A conquista do espaço urbanizado, ao mesmo tempo que implica em derivações de vulto no quadro ecológico, passa, através do seu desenvolvimento temporal, por várias feiçốes da massa edificada, de acordo com a própria evolução e diversificação das funçôes urbanas. E este próprio evoluir é condiçẫo básica para que a cidade seja capaz de alterar as condições climáticas locais até adquirir atributos tais que a possam dotar de um caráter de clima "urbano". As condiçóes da São Paulo do início dos anos trinta e as atuais são imensamente diferentes. Naquele já remoto então dos anos trinta a "São Paulo da Garoa" tinha nessa feição um caráter que se prendia ainda às condiçôes geo-ecológicas locais que eram e principiavam a sofrer alteraçóes. A São Paulo, substancialmente mais quente e poluída de hoje é um complexo campo de análise da metrópole subtropical, (MONTEIRO, 1990, p. 87)

Os apontamentos do autor demonstram a relevância na articulação da dimensão socioespacial nos estudos de clima urbano, deixando explícito que o desenvolvimento temporal na cidade transforma as funçóes urbanas e consequentemente modifica as formas, alterando as condiçóes climáticas pretéritas, fazendo com que a cidade adquirira condiçôes climáticas distintas de décadas anteriores, produzindo-se um clima urbano.

A sociedade e o espaço devem ser analisados vinculadamente nos estudos de clima urbano, já que a sociedade produz o espaço geográfico, produz socialmente o espaço urbano, alterando as características superficiais pretéritas, transformando e produzindo uma nova paisagem que irá gerar condiçôes microclimáticas distintas da paisagem anterior.

A respeito da paisagem urbana, Carlos (2013) aponta que na paisagem da metrópole paulista, o verde cede lugar aos prédios, casas e ruas. Evidenciando que a paisagem na cidade é transformada ininterruptamente, sendo o verde suprimido para dar lugar ao concreto e asfalto no processo de produção do espaço e extensão da mancha urbana. Em decorrência dessas características teremos usos diferenciados dos espaços na cidade, visto que eles se (re)produzem de forma desigual e contraditória, gerando as desigualdades socioespaciais, reflexos na paisagem urbana. 
A cidade é uma concentração de pessoas exercendo, em função da divisão social do trabalho, uma série de atividades, desencadeando uma disputa de usos, sendo que os bairros do extremo leste da cidade exercem predominantemente a função de bairro dormitório, no qual os equipamentos urbanos estão presentes em menor quantidade e diversidade, expressão de uma produção do espaço urbano desigual.

O objetivo deste artigo é fazer uma discussão que contribua para o entendimento do clima urbano como construçáo social, produto do processo de produçáo do espaço urbano, tendo como estudo de caso parte da periferia da zona leste da cidade de Sáo Paulo.

\section{O CLIMA URBANO COMO CONSTRUÇÁO SOCIAL NO CONTEXTO DA PRODUÇÃO DO ESPAÇO URBANO PERIFÉRICO DA ZONA LESTE DE SẨO PAULO}

O clima urbano como construção social deve ser entendido em conjunto com a produção do espaço urbano. Nesse sentido, entender a produção do espaço urbano nas periferias da zona leste da cidade de São Paulo é fundamental para o entendimento do clima urbano dessa localidade. A cidade de São Paulo, como as demais cidades brasileiras, foi construída sob a égide do modo de produção capitalista, de forma desigual e contraditória, que demarca o uso diferenciado da cidade. A segregação socioespacial é o produto da desigualdade social, da sociedade dividida em classes, na qual uma parcela da sociedade é imputada à segregaçáo e a outra opta pela auto-segregaçáo.

Seabra (2004) aponta que a urbanização pensada como mobilidade geral do trabalho em função da indústria propicia um periferização generalizada. O apontamento feito pela autora pode ser generalizado para o extremo leste da cidade de São Paulo, mais especificamente para os bairros da Vila Curuçá, Itaim Paulista e São Miguel Paulista.

A formação desses bairros iniciou-se muito antes da chegada da indústria. Segundo Fontes (2008), no período colonial (séculos XVI e XVII) já havia aldeamentos indígenas e missóes jesuítas, apesar da história do bairro ter sido alterada profundamente nos anos 1930, com a instalação da Companhia Nitro-Química Brasileira.

A figura 1 nos permite visualizar a região de São Miguel Paulista, Itaim Paulista e Ermelino Matarazzo, na década de 1940. Nota-se que existiam poucos arruamentos, as áreas nas quais se concentravam estavam no entorno das indústrias: Nitro-Química e Celosul. 
Figura 1 - Região de São Miguel Paulista e entorno em 1945. Mapa elaborado por Aroldo de Azevedo em 1945

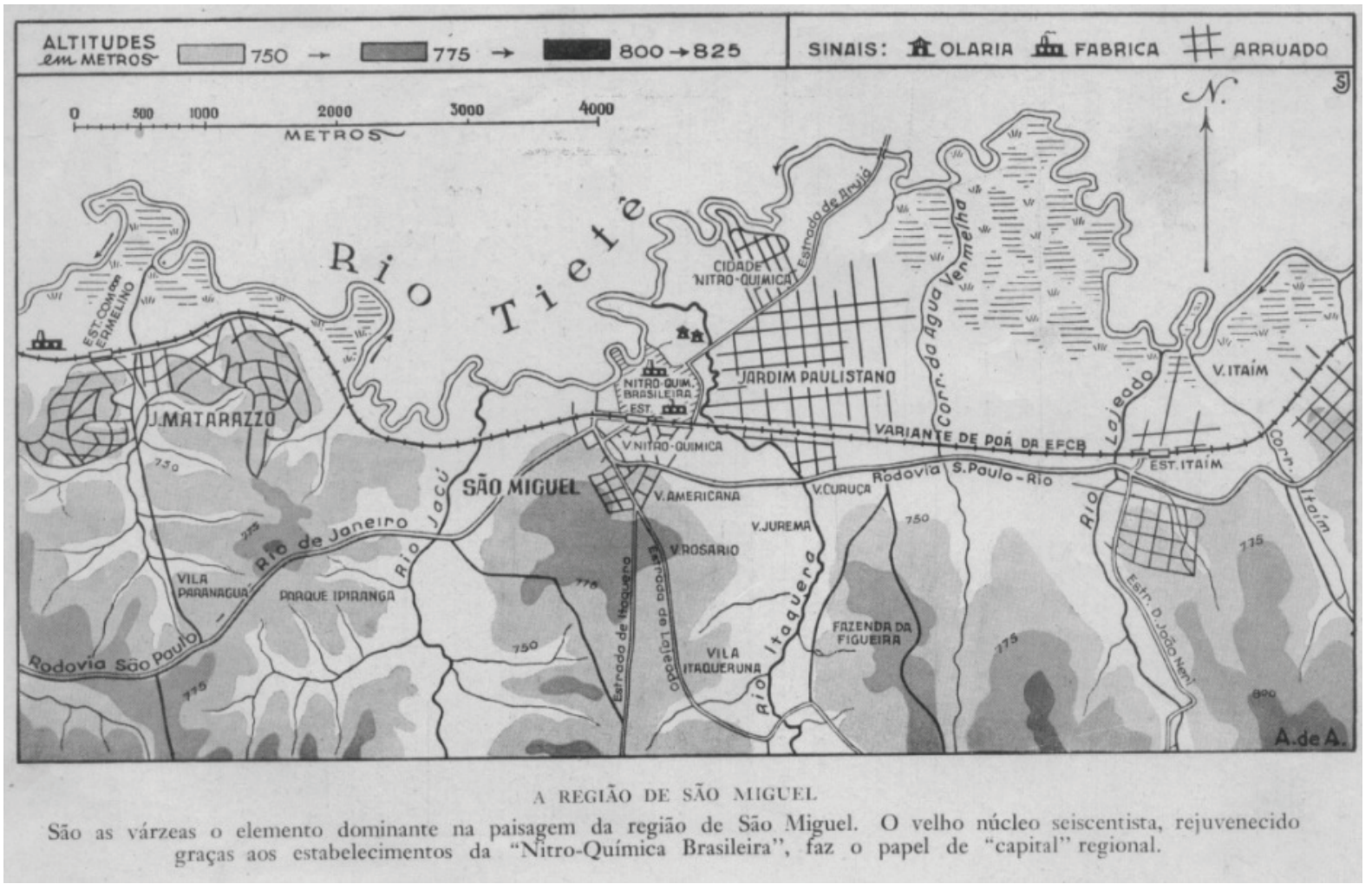

A instalação da indústria, no bairro de São Miguel Paulista, acabou desencadeando o crescimento demográfico no bairro na década de 1930, atraindo um contingente significativo de migrantes, sobretudo nordestinos e, consequentemente, isso se estendeu para outros bairros do entorno, como a Vila Curaçá e Itaim Paulista, ${ }^{22}$ influenciando na expansão urbana da cidade. Azevedo (1945, p. 133), confirma, dizendo:

[...] Na várzea do Itaquera, ao longo da Rodovia São Paulo-Rio, outras "vilas" operárias também existem a Cidade Nitroperária, a Vila Curuçá. Todos são núcleos de formação recente, resultantes da instalação ali dos estabelecimentos da "Companhia Nitro-Química Brasileira [...]

Azevedo (1945) também sinaliza que os núcleos vizinhos tinham uma função residencial, pois a população exercia suas atividades nas duas grandes fábricas da região, a Nitro-Química em São Miguel Paulista e a Celosul em Ermelino Matarazzo, ou no centro da cidade de São Paulo.

As motivações econômicas para a instalação da Nitro-Química em São Miguel Paulista, dizem respeito também a alguns fatores locacionais e à intervenção estatal,

2 Hoje, ambos são distritos únicos, pertencentes à subprefeitura do Itaim Paulista, mas naquele momento reportavam-se a São Miguel Paulista. 
que viabilizaram a acomodação da indústria no extremo leste da cidade de São Paulo. De acordo com Bomtempi (1970), depois do advento da linha de ônibus em 1930 e da variante da estrada de ferro em 1932, instalava-se no bairro, em 1935, a Companhia Nitro-Química Brasileira, iniciando a fase industrial de São Miguel. Além dos fatores locacionais citados, de acordo com Azevedo (1945, p. 137):

[...] as origens prendem-se a crise econômica de 1929 e o fechamento de uma grande fábrica de seda artificial existente nos Estados Unidos e pertencente à "Tubize Chatillon Corp." Tendo sido deliberada sua remoção para a América do Sul, foi a mesma adquirida por alguns capitalistas de nosso Estado e iniciada sua construção em 1935. O local oferecia muitas vantagens, que justificaram a preferência recebida: fáceis meios de comunicação, graças à via-férrea e à estrada de rodagem; proximidade do rio Tietê, que passou a fornecer água, consumida em enorme quantidade; o baixo custo do terreno, então desvalorizado.

Hoje, as instalaçóes abrangem uma área de $200.000 \mathrm{~m}^{2}$ e erguem-se ao pé da estação ferroviária, na própria várzea do grande rio. Nelas trabalham mais de 4.000 operários, dos quais 1.200 mulheres, que vêm diariamente da Capital pela via-férrea ou procedem do próprio local ou de suas vizinhanças (Itaquera, Itaim, Poá). Sua produção consiste em seda artificial, algodão-pólvora e outros produtos químicos (ácido sulfúrico, ácido clorídrico, sulfatos, nitratos etc.), estando trabalhando também em produtos necessários à defesa do País. Boa parte da matéria-prima ali manipulada vem do estrangeiro (ácidos e enxofre dos Estados Unidos, salitre do Chile), destinando-se sua produção ao consumo interno.

É importante destacar que fenômenos que aparentemente não dizem respeito ao lugar acabam tendo reflexo no bairro de São Miguel Paulista. A crise econômica que acontecia nos Estados Unidos acabou tendo reflexo no Brasil, na cidade de Sáo Paulo, no bairro de São Miguel Paulista, com a instalação da indústria, após seu fechamento no país de origem.

Além disso, vale ressaltar a capacidade da indústria para os padróes da época, considerada uma indústria de grande porte que produzia uma diversa gama de produtos químicos, tanto é que foi considerada de interesse nacional, recebendo incentivos do governo federal, ou como cita Lopes (2011) e Paiva (2004) "com generoso apoio do governo Vargas mais de dezoito mil toneladas de equipamentos e maquinaria foram transferidas da fábrica original na Virgínia para São Miguel”. Vale destacar que Getúlio Vargas esteve na inauguração da Companhia Nitro-Química.

A industrialização de São Miguel foi modesta em relação à faixa São Caetano-Santo André, como sinalizou Langenbuch (1971). No entanto, mesmo sendo modesta gerou transformaçóes no espaço geográfico, produzindo uma paisagem urbana com características predominantemente residenciais.

A instalação da indústria no bairro de São Miguel Paulista acabou alterando a dinâmica do bairro e do extremo leste da cidade, ela trouxe consigo um contingente 
significativo de migrantes, predominantemente nordestinos. Junto a essa mobilidade populacional adquire força o processo de especulação imobiliária e expansão urbana que juntos são essenciais para se compreender as transformaçôes da paisagem urbana, como mostra Bomtempi (1970, pp.159-160):

Imediata decorrência da chegada dos estabelecimentos industriais, manifestou-se uma radical transformação dos campos. Antes da instalação da Nitro-Química Brasileira distribuía-se a pequena povoação ao redor das olarias, nas proximidades do Tietê. Reforçando-se os números populacionais, o bairro ganha arruamentos em pontos mais afastados e em todas as direçóes. Chácaras e capoeiras cedem lugar às vilas operárias, onde residem não só os trabalhadores da indústria local como também dos estabelecimentos de outras partes da cidade. É a fase dos loteamentos, ensaiada nas primeiras décadas do século e reanimada com êxito a partir de 1935. Democratiza-se a propriedade imobiliária, fragmentada em milhares de pequenos lotes vendidos a longo prazo e onde se erguem modestas casas sempre por terminar.

A produção do espaço periférico vai se configurando de forma (des)organizada e o verde cede lugar ao cinza do concreto, ao laranja dos tijolos de alvenaria, presentes nas moradias inacabadas, sempre a vir a ser. $\mathrm{O}$ espaço urbano é vendido e produzido como mercadoria. Carlos (2013, p. 19) diz que "os pedaços da cidade são vendidos, no mercado, como mercadorias; árvores são destruídas, praças transformadas em concreto". Ela ainda difere as cores, tamanho dos terrenos, arborização dos bairros periféricos em oposição aos bairros de classe média e alto padráo:

[...] a autoconstrução - em bairros periféricos e afastados geralmente, sem infraestrutura. De outro, os apartamentos de classe média e os de alto padrão com áreas de $100 \mathrm{~m}^{2}$; e os sobrados, as mansóes em ruas arborizadas pontilhadas por guaritas com guardas uniformizados. O colorido diferenciando-se em função dos bairros da cidade; ora é cinza (do concreto), passando pelo vermelho (duas ruas sem asfaltos, das vertentes desnudas sem cuidado) até o verde das ruas arborizadas [...] (CARLOS, 2013, p. 19).

A periferia urbana possui características distintas, os terrenos têm um aproveitamento máximo, em geral, as casas são grudadas umas nas outras, as ruas não são arborizadas, existem poucos espaços livres, muitas áreas concretadas e, hoje em dia, asfaltadas, isso cria condiçóes microclimáticas diferentes dos bairros de classe média e alto padrão que são o contraponto dos bairros periféricos. Os bairros de classe média e alto padrão possuem grandes áreas verdes, muitas vezes os quintais são equivalentes ou superiores às praças públicas dos bairros periféricos, as ruas costumam ser arborizadas, as casas não são coladas umas nas outras. Para Carlos (2013, p. 40) "a paisagem urbana é o choque dos contrastes, das diferenças. Contrastes de tipo e diversidade de utilização da cidade: usos do solo".

Os contrastes observados na paisagem urbana evidenciam a desigualdade socioespacial, corroborando com a ideia de que o clima urbano pode ser em parte entendido como uma construção social, visto que a produção do espaço é desigual, determina 
o uso do solo na cidade e cria condiçóes microclimáticas diferentes, tornando muito mais vulnerável a populaçáo de baixa renda do que a população de classe média e alta às repercussóes do clima e tempo no espaço. Carlos (op. cit., p. 42), ilustra ao afirmar que as "inter-relaçóes entre os fatores físicos e os sociais será a expressão material da unidade contraditória de relaçóes entre a sociedade e a natureza, seja esta primeira ou já transformada”.

O espaço habitado e produzido de forma desigual e contraditória, segundo Carlos (2013, p. 24), evidencia as desigualdades que podem ser percebidas no espaço urbano, através da paisagem:

A paisagem é humana, tem a dimensão da história e do socialmente reproduzido pela vida do homem. É expressão de um modo de vida. A desigualdade que pode ser percebida "no olhar-se a paisagem" é consequência dos contrastes decorrentes do processo de produção do espaço urbano. As relações criam formas e as funções devem ser cumpridas.

A paisagem acaba sendo um referencial importante para a compreensão do uso do solo urbano e da historicidade do lugar, do bairro e da cidade; nela encontramos fragmentos do passado, elementos do presente e projeçóes do futuro, portanto, é um registro de elementos do passado, uma fotografia do presente e uma sinalização do futuro. Ela guarda marcas importantes que nos permitem compreender as inter-relaçóes entre os fatores físicos e sociais, sendo um dos pontos de partida para o estudo do clima urbano.

Os estudos de Geografia Urbana tecem algumas reflexôes sobre a paisagem, importantes para a compreensão do clima urbano possibilitando analisar o clima urbano também como uma construçáo social, inter-relacionando elementos naturais e sociais para compreensão do mesmo. Carlos (2013) tece reflexóes a respeito da paisagem que nos ajudam a pensar as interfaces entre Climatologia Geográfica e Geografia Urbana, como as contradiçóes sociais que emergem na paisagem, os contrastes e as desigualdades de renda que afloram. Uma característica da desigualdade é a segregaçáo espacial, conforme Carlos (2013, p. 78):

[...] a segregaçáo espacial, tanto das pessoas de maior rendimento, quanto das de menor poder aquisitivo. As de maior rendimento tendem a localizar-se em bairros arborizados, amplos, com completa infraestrutura, em zonas em que o preço da terra impede o acesso a "qualquer um". Há também os condomínios exclusivos e fechados, com grandes áreas de lazer e até shopping, com grande aparato de segurança e amplos estacionamentos. Os de baixo rendimento têm como opção os conjuntos habitacionais, geralmente localizados em áreas distantes dos locais de trabalho. São os bairros operários com insuficiência ou mesmo ausência de infraestrutura; e as áreas periféricas onde abundam as autoconstruções, além das favelas que afloram no seio da mancha urbana.

A segregação espacial, entendida a partir do processo de produção desigual do espaço, tem reflexos no cotidiano das pessoas, sobretudo nas camadas de baixo poder 
aquisitivo da sociedade, como evidencia Armond (2014, p. 45) "a produção desigual do espaço acaba por contribuir para a existência de diferentes susceptibilidades e/ou riscos e vulnerabilidades de acordo com as diferentes formas de reprodução social da existência de sujeitos das diferentes classes sociais".

A produção desigual do espaço promove a segregação socioespacial, por meio de um processo de expansão urbana, atrelado à especulação imobiliária, criando e consolidando a periferia como espaço de moradia da população pobre. Na cidade de São Paulo isso tem seu auge, segundo Fontes (2008, p. 94):

A partir dos anos 1950, a cidade de São Paulo passava, portanto, por um processo contínuo de criação e consolidação de sua periferia como espaço residência da população pobre. $\mathrm{O}$ padrão anterior de adensamento dos trabalhadores com a proximidade da residência e local do trabalho como regra vai rapidamente se desestruturando ao longo daquele período. Ocorria uma aguda descentralização da moradia operária, espalhamento das casas dos trabalhadores por diversos e afastados bairros de São Paulo e cidades vizinhas e, em boa parte dos casos, tornando distantes seus empregos.

A periferização da classe trabalhadora, segundo o autor, no período de 1940 e 1970 foi acompanhada da expansão não só da mancha urbana, mas também da propriedade da moradia, gerando uma queda na porcentagem de domicílios alugados no município.

A possibilidade da casa própria para esses trabalhadores, no entanto, se realizava por meio da autoconstruçáo, como mostra Kowarick (1986) apud Fontes (2008, p. 95):

[...] para a maioria dos trabalhadores a possibilidade da casa própria na capital paulista somente podia ser realizada através da autoconstruçấo da moradia nos lotes periféricos adquiridos à prestação e desprovidos de qualquer infraestrutura. A construção era, portanto, lenta e parcelada, realizada com os parcos recursos próprios e a ajuda de familiares e amigos, utilizando os fins de semana e os períodos de folga. Em 1980, estimava-se que $63 \%$ das moradias da Grande São Paulo haviam sido construídas através do processo de autoconstrução, sendo que na capital cerca de metade das residências teria sido erguida dessa forma $[\ldots]$

O processo de autoconstrução é uma característica marcante no processo de produção do espaço no extremo leste da cidade, somado a aumento populacional na cidade. No ano de 1940 a população era de 1.311 .133 habitantes e em 1966 correspondia a 5.115 .856 habitantes. Em decorrência disso, a cidade passou a exercer forte pressão sob sua periferia. Nesse contexto que ocorre a expansão do bairro de Sáo Miguel Paulista, abarcando os bairros da Vila Curuçá e Itaim Paulista (LANGENBUCH, 1971).

A lógica do processo de produção do espaço urbano se dá de forma desigual e contraditória, orbitando sempre os interesses do capital privado, do mercado imobiliário, 
via intervenção do Estado. Essa combinação de fatores não é recente, desde o século XIX essa lógica já opera na cidade de São Paulo, como nos aponta Paiva (2004, p. 45):

A história da apropriação do espaço urbano na cidade de São Paulo sempre guardou contradiçôes, muitas delas giraram em torno dos interesses de um mercado imobiliário dual. Desde a redefinição do Código de Posturas em 1886, a proibição da construção de cortiços na região central da cidade apontava para a tendência em alocar a população pobre da periferia da cidade e a utilização da zona central como espaço de apropriação dos grupos mais abastados.

O uso do solo urbano é normatizado pelo Estado, com o fim de garantir que os interesses do mercado imobiliário sejam atendidos e os especuladores operem na venda da cidade, em pedaços e parcelas a quem pode pagar. Assim, o local de moradia é ditado pelo quanto você pode pagar, como nos mostra Alves (2010, p. 19): "as melhores parcelas do solo urbano só podem ser 'usadas' por quem por elas puder pagar”.

Segundo Paiva (2004), para o capital especulativo, a abertura de novas áreas significou a elevaçáo do lucro por meio da apropriação da renda da terra. Das antigas chácaras e áreas desvalorizadas surgiram loteamentos que deram origem a muitos bairros atuais da cidade e para o capital industrial, o deslocamento e construção de fábricas nessas áreas, representou um custo menor de fixação.

Os dois casos citados pelo autor, tanto do capital especulativo, quanto do capital industrial, denotam o processo de crescimento do bairro de Sáo Miguel Paulista com a instalação da Companhia Nitro-Química e a abertura de loteamentos com a chegada da população migrante que ali se instalou, a partir da década de 1930.

A especulação imobiliária se capilarizou na periferia com a certeza do lucro certo e garantido, em decorrência da expansão urbana que não tardaria a chegar, segundo Langenbuch (1971, p. 83):

A especulação imobiliária, por sua vez, provoca sempre a aquisição de lotes visando apenas fins lucrativos, os quais consequentemente permanecem desocupados. Por outro lado, em função do espantoso crescimento da cidade, o comprador de lotes, mesmo afastados, seguramente tinha a consciência ou a impressão de que a cidade não tardaria a alcançar o local.

O autor nesse excerto trata apenas de um momento de produção do espaço na periferia, por volta da década de 1930, baseado na venda de lotes e na autoconstrução, tendo como principal agente a iniciativa privada. Todavia, cabe destacar outros dois momentos posteriores ao da expansão urbana horizontal.

O segundo momento ocorre em meados dos anos 2000, com a intervenção do Estado, por meio da criação dos Conjuntos Habitacionais da Companhia de Desenvolvimento Habitacional e Urbano (CDHU), momento em que a periferia começa a sofrer uma expansão vertical, via intervenção estatal.

O terceiro momento ocorre na segunda metade dos anos dois mil e vem se acentuando nos últimos anos. Esse período tem as construtoras como os principais 
agentes da produção do espaço urbano na periferia, por meio da construção de prédios e casas geminadas.

No período atual nos deparamos com escassez do espaço: se antes havia as antigas chácaras, fazendas e muitas áreas livres, hoje passamos da condição de abundância para a de raridade. Essa raridade faz com que novas formas de (re)produçáo do espaço surjam na periferia, com a (re)produçáo vertical e horizontal do espaço, em antigas chácaras e áreas livres. Suprimindo as poucas áreas livres e verdes que existem nos bairros periféricos, alterando as condiçôes microclimáticas, produzindo desconforto térmico.

Ainda a respeito da verticalizaçáo da periferia e do segundo momento de produção do espaço, é importante destacar o caráter segregador e (des)ordenado, como nos mostra Damiani (1994, p. 97) "Em nosso país, os grandes conjuntos habitacionais aparecem, entre outras, como solução habitacional barata, relativamente, e necessariamente para determinada faixa da população que, de outra forma concentrar-se-ia em favelas e cortiços".

A autora evidencia o caráter habitacional planejado para a população de baixo poder aquisitivo pelo Estado, que é a solução mais barata, homogênea, estéril, a pobreza da vida urbana e "denuncia o aprofundamento da decomposição estrutural do país: 'didatização forçada dos procedimentos, excessiva racionalização construtiva, economismo de espaços ultradensos"” (DAMIANI, 1994).

Segundo Damiani (1994, p. 105):

Essas soluções lógicas no plano urbanístico, na realidade são versões políticas importantes e impositivas de um modo de vida. Uma concepção segregada e segmentada, estratificada de política urbana é uma concepção possível a partir de bases modernas.

Os argumentos da autora deixam explícito como o urbano é pensado, programado e concretizado para a populaçáo de baixo poder aquisitivo, o caráter segregador imposto, por meio dos planos urbanísticos propostos ou gerenciados pelo Estado. Todavia, cabe destacar que esses projetos, que encontramos no extremo leste da cidade de Sáo Paulo, são exemplos claros de políticas de Estado que acabam não só influenciado no modo de vida, mas também no microclima dessas áreas, já que as áreas verdes, arborização urbana e corpos d'águas são inexistentes e os que existiam deixaram de existir para vir a ser "moradia". Essas ações têm reflexos e estão presentes na paisagem urbana, como podemos visualizar na figura 2 . 
Figura 2 - Fotos da avenida Marechal Tito (antiga Rodovia São Paulo-Rio)

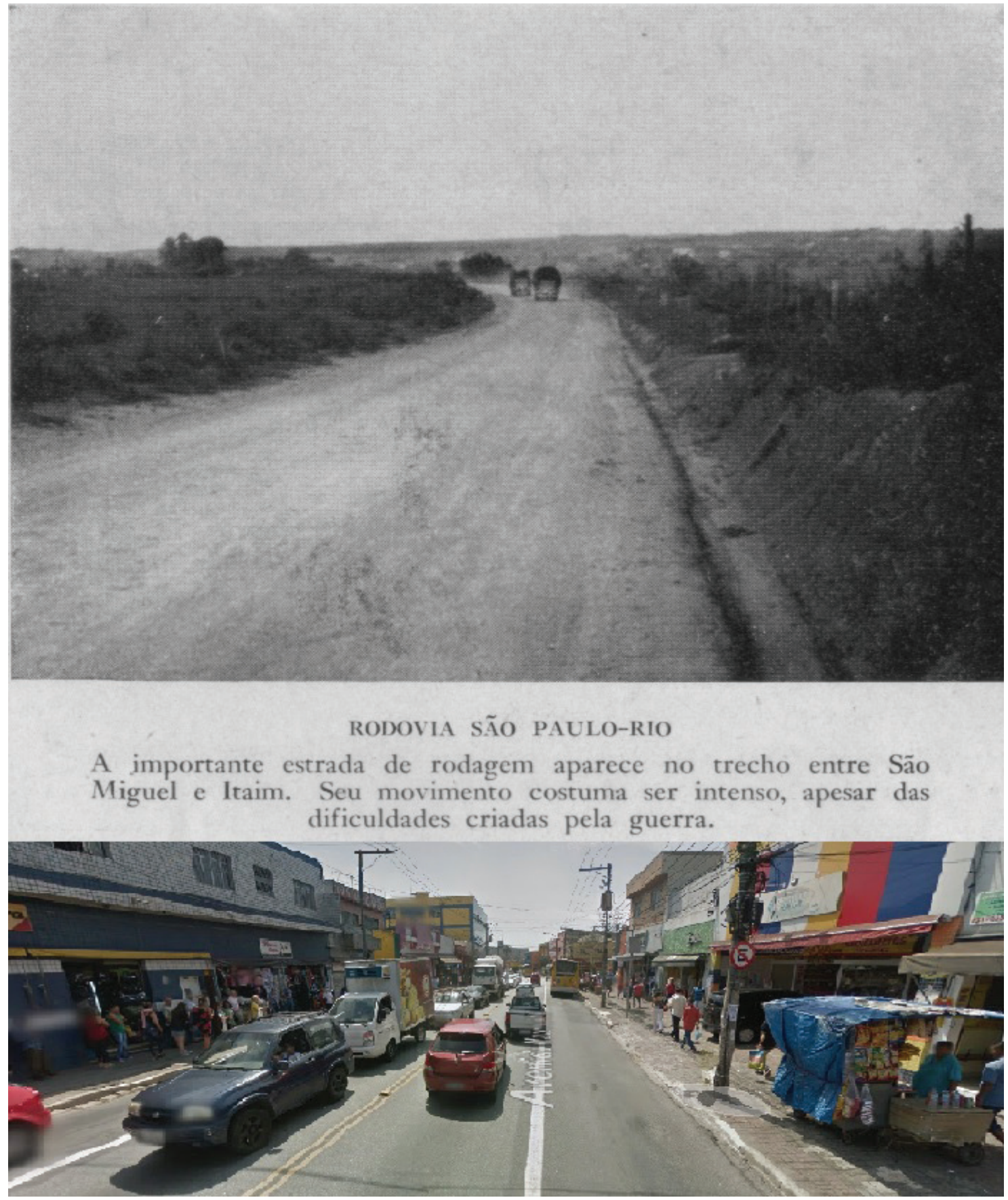

Fonte: Azevedo, 1945; Google Earth, 2016.

As formas dos conjuntos habitacionais e dos bairros periféricos expressam contradiçóes do processo de produção do espaço urbano e revelam as desigualdades e a segregação espacial, que aparecem no acesso a serviços básicos de infraestrutura, como áreas verdes, praças, arborização, os meios de consumo coletivo nos bairros periféricos, em contraposiçấo aos bairros de classe média e alta padrão, nos quais esses meios de consumo fazem parte do "projeto urbanístico". 
Essas questôes vêm sendo ressaltadas ao longo do trabalho para evidenciar que os bairros possuem cores, no seu sentido mais abrangente, são servidos de equipamentos urbanos de forma diferenciada, são estratificados socialmente, logo, os traçados urbanísticos são distintos entre si, sujeitando a população de menor poder aquisitivo às piores condiçóes urbanas, tanto do ponto de vista social, quanto ambiental.

O espaço urbano guarda a dimensão da natureza, ele é produzido para atender determinadas necessidades da sociedade, possui uma dimensáo social e natural, adquirida ao longo da história. A relação sociedade-natureza produz um espaço social. A dimensão social do espaço produzido implica na criaçáo de microclimas diferentes no espaço urbano, por meio das transformaçóes da primeira e segunda natureza, a incorporaçáo de materiais construtivos.

Segundo Cruz (1998, p. 12):

Sendo o espaço geográfico uma construção social, as relações homem-natureza são intermediadas, sempre, pelas relaçóes que se estabelecem entre os homens, pelas relaçôes sociais. Não há relação homem-natureza que não seja o resultado, a tradução, no espaço, das relaçóes sociais.

Desta forma, os problemas ambientais nada mais são do que a materialização, no espaço, das relaçóes sociais.

A materialização das relações sociais no espaço geográfico guarda contradições do processo de produção do espaço que são escancaradas na cidade e percebidas na paisagem urbana, como nos mostra Carlos (2007, p. 36):

[...] ao lado de áreas arborizadas, bem cuidadas, amplas e vigiadas da metrópole, estendem-se imensas áreas que os urbanistas gostam de chamar de "degradas", onde vive uma grande parte da população da metrópole, correspondentes aos menores extratos de renda, que habitam cortiços, as favelas, além dos que moram nas praças e ruas da cidade [...]

As habitações mais "pobres" são localizadas nos terrenos mais baratos, nos lugares mais distantes, menos servidos de equipamentos urbanos, próximas às áreas sujeitas a movimentos de massa, enchentes, alagamentos e sujeitas a fatores adversos do clima.

Os bairros da cidade se diferenciam entre si por um conjunto de características, a paisagem urbana evidencia isso, como nos mostra Carlos (2007, p. 98):

A paisagem vai revelando esse processo, os lugares da metrópole vão se diferenciando, por exemplo, pela fisionomia. A cor das áreas "ricas", por exemplo, é verde (da vegetação abundante se comparada com outros lugares), com casas amplas e de variadas dimensóes e estilos, muitas declaram uma arquitetura arrojada, e as ruas estão quase sempre vazias. As áreas onde o preço do metro quadrado é menor, as moradias sáo menores, umas ao lado das outras em terrenos pequenos, com pouco ou nenhum verde, em alguns lugares, apresentam-se amontoadas num misto de auto-construção e favelas, construídas em terrenos pouco valorizados onde se aglomera uma massa de trabalhadores e desempregados, em locais cada vez mais distantes daquele de 
trabalho (o que os obriga a gastos excessivos de horas de transporte, inúmeras baldeaçóes, diminuindo mais ainda o tempo de lazer, além dos custos que consome o já "minguado" salário do trabalhador). A tônica é a quase ou total inexistência de infra-estrutura (rede de água, luz, esgoto, limpeza pública, asfalto, escolas, prontos-socorros, hospitais, etc.) caracterizando-se como áreas de condiçóes sub-humanas de moradia. Mas com ruas animadas, revelando que são lugares de realização da vida e não somente da sobrevivência.

Os lugares na metrópole são diferenciados, modificados e segregados. As características descritas pela autora no excerto acima, mostram isso tanto do ponto de vista social, quando fala dos lugares, e esses lugares são habitados por pessoas, como do ponto de vista ambiental, quando aborda as diferenças físicas, disposição, dimensão, estilos das moradias e arborização dos bairros. Todos esses aspectos levantados pela autora, decorrentes do processo de produçáo do espaço, têm reflexos no microclima, produzindo um clima urbano, com bairros que possuem microclimas distintos.

A natureza é transformada, apropriada e dela se produz materiais distintos, utilizados nas moradias de forma diferenciada. Portanto, o clima urbano é também uma construção social, quando partimos da tese de que ele é modificado frequentemente no processo de produção do espaço urbano. Mas, se o processo é desigual e contraditório, logo, os efeitos do clima serão desiguais.

Quando Carlos $(2007,2013)$ e outras autoras nos apresentam as distinções existentes nos bairros de classe média, baixa e alta, notamos que há diferenças, como arborização ou não das ruas, jardins nos quintais, casas separadas ou juntas umas das outras, maiores ou menores, número menor ou maior de moradores por domicílio, dentre outras características, decorrentes do processo de produçáo do espaço urbano. Podemos inferir diferenças e alterações no balanço de radiação, no albedo, circulação do ar, aquecimento diferencial dos materiais construtivos. Segundo Sant'Anna Neto (1998, p. 122):

Quando tratamos de áreas urbanas, o clima original é constantemente modificado pela construçâo do espaço urbano, uma vez que é alterado, entre outros fatores, o balanço de energia, em funçâo da concepção de cidade estabelecida pela civilização capitalista ocidental.

As alteraçóes na paisagem natural e urbana podem trazer consequências adversas à sociedade, causando enchentes, inundaçóes, queda na umidade relativa do ar e aumento das temperaturas. Como elucida Sant'Anna Neto (1998, p. 126):

A expansão das áreas urbanas provoca modificações significativas na paisagem natural. A substituição da vegetação por áreas construídas (cimento, concreto e alvenaria), a pavimentação asfáltica das ruas, a concentração de parques industriais e o adensamento populacional (incluindo-se aí todas as atividades humanas inerentes à sua vida na cidade, como transporte, alimentação etc.), são responsáveis pelo aumento da temperatura nas cidades.

Esta elevação da temperatura nas áreas urbanas ocorre em função de vários fatores. A verticalização das construçôes, por exemplo, cria um verdadeiro 
"labirinto de refletores", em que a energia proveniente do sol é refletida pelos edifícios, aquecendo o ar. A diminuição da evaporação, por outro lado, ocorre pela redução das áreas verdes e canalização dos rios e córregos, além da captura das águas pluviais, acarretando na atmosfera uma pequena capacidade de resfriamento do ar.

Os argumentos levantados pelo autor confirmam em grande parte a gênese do clima urbano como um processo social, derivado do processo de produçáo do espaço e que tem repercussóes diferentes, já que a produção do espaço é desigual e contraditória. Portanto, é relevante fazermos um recorte de classe, pois as repercussóes do clima e tempo em diferentes estações do ano serão diferentes nos bairros dos "ricos" e nos bairros dos "pobres", tendo variados níveis de vulnerabilidade e segregação.

As repercussões do clima ocorrem no espaço, num espaço desigual e contraditório, logo, seus efeitos serão desiguais na sociedade e no espaço, por isso incorporamos nessa análise a dimensão social na interpretação do clima urbano, não considerando que o clima urbano pode ser estudado de forma isolada, somente com a dimensão climática, como nos mostra Sant'Anna Neto (2008, p. 61):

[...] a necessidade de se incorporar a dimensão social na interpretação do clima na perspectiva da análise geográfica. Isto significa, necessariamente, compreender que a repercussão dos fenômenos atmosféricos na superfície terrestre se dá num território, transformado e produzido pela sociedade, de maneira desigual e apropriado segundo interesses dos agentes sociais.

[...] o efeito dos tipos de tempo sobre um espaço construído de maneira desigual gera problemas de origem climática, também desiguais. A entrada de um sistema atmosférico, como uma frente fria (frente polar atlântica), por exemplo, se espacializa de maneira mais ou menos uniforme num determinado espaço, em escala local. Entretanto, em termos socioeconômicos, este sistema produzirá diferentes efeitos em função da capacidade (ou possibilidade) que os diversos grupos sociais têm para defenderem-se de suas açóes.

Se o resultado concreto da entrada desta frente fria, em área urbana, for a queda de precipitação em grandes quantidades, e se o produto final desta ação desembocar numa enchente, tem-se que admitir que muito provavelmente as áreas mais atingidas pelas águas deverão ser aquelas onde os equipamentos urbanos e o poder público funcionam de forma mais precária, pois as enchentes não atingem e não afetam a todos da mesma maneira.

O autor incorpora elementos da dimensão social, importantes na análise geográfica do clima, nos mostrando que não basta entendermos os processos, dinâmicas, modelos e estruturas temporais, mas o significado desses processos inseridos nas dimensóes socioeconômica e socioambiental. A abordagem proposta por Sant'Anna Neto (2008), denominada como Geografia do Clima "leva em consideração o conforto humano e ambiental, vulnerabilidade socioambiental e a produção do espaço urbano". Partimos da proposta do autor, entendendo a Geografia do Clima em sua complexidade, articulando elementos sociais e naturais para a compreensáo do clima urbano também como uma construção social. No entanto, levamos também em consideração os apontamos 
feitos por Carlos Augusto de Figueiredo Monteiro que influenciaram de forma expressiva as propostas de Sant'Anna Neto. Monteiro (1990) já tecia reflexóes a respeito dos estudos de clima urbano no Brasil, apontando que para serem geográficos não deveriam desconsiderar a condição urbana:

É preciso não esquecer que a abordagem geográfica da cidade não pode descartar, nesse processo de evolução histórica, os aspectos culturais ligados à trama do socioeconômico. Assim, parece que os estudos dos climas urbanos no Brasil, para serem geográficos, não podem ignorar as variáveis inerentes a sua própria "condiçâo urbana". Neste particular as cidades do mundo ocidental economicamente hegemônico são mais simples. O estudo de clima urbano entre nós não deve ser apenas um ensaio em "tropicologia" mas deve estar associado a este caráter socioeconômico que lhe é peculiar e que está indelevelmente marcado no "urbano". (MONTEIRO, 1990, p. 89).

O autor não aponta só a condição urbana, mas o caráter socioeconômico, inerente aos estudos de clima urbano, num país marcado por forte desigualdade social e segregação socioespacial.

O entendimento do clima urbano também como uma construção social, portanto, nos obriga a entender o processo de produção desigual do espaço e o clima urbano e, ao mesmo tempo, as consequências ambientais desiguais na cidade, em decorrência da segregação socioespacial e os padrôes de uso e ocupação do solo urbano distintos.

Os bairros do extremo leste da cidade de São Paulo possuem características completamente distintas dos bairros de classe média e alto padrão, a população que vive nesses bairros está sujeita às condiçôes ambientais desfavoráveis do ponto de vista climático, sobretudo no que diz respeito ao conforto térmico.

A lógica segregacionista resulta na ocupação das áreas periféricas da cidade, configurando áreas com elevados adensamentos populacionais, sujeitos às enfermidades urbanas, característica dos bairros segregados da cidade, como os do extremo leste.

A produção do espaço urbano e suas consequências socioambientais são elucidadas por Sant'Anna Neto (1998, p. 45):

Como a produção do espaço urbano segue a lógica da reprodução capitalista, portanto gerador de espaços segregados e fragmentados, longe de se produzir um sistema que respeite e se adapte às condições ambientais e naturais, é de se esperar que esta contradição resulte em impactos altamente sensíveis aos diversos grupos sociais que habitam a cidade de forma também desigual, tornando as desigualdades sociais, ainda mais agudas.

Deste modo, o clima intra-urbano será diferente, as condições microclimáticas dos bairros periféricos da zona leste, com população predominantemente, são distintas das condiçôes do Jardim Europa, bairro de alto padrão, na zona oeste da cidade de São Paulo, logo, os efeitos adversos do clima afetam de forma desigual a população mais "pobre". 


\section{CONSIDERAÇÓES FINAIS}

A pesquisa demonstrou que podemos entender o clima urbano também como uma construçáo social, partindo do pressuposto de que o processo de produção desigual do espaço urbano transforma a paisagem, dando novas feiçóes, que têm reflexos diretos nos microclimas da cidade.

A tentativa de compreensão do processo de urbanização se mostra relevante nos estudos de clima urbano, pois a partir da análise do processo podemos compreender o clima urbano como um fator social e não somente natural. Os reflexos da urbanizaçáo como algo marcante, sobretudo nos bairros com população de baixa renda, nos quais o padrão de urbanização contribui para os efeitos adversos do clima e do tempo, de forma diferente dos bairros de classe média e alta.

A segregação socioespacial é outro elemento chave para entendermos as diferenças inter-urbanas, fazendo um recorte de classe, pois ela acaba por condicionar a populaçáo de baixa renda as piores condiçóes de qualidade ambiental na cidade, acesso escasso aos equipamentos urbanos e condições microclimáticas distintas da população com maior poder aquisitivo. Portanto, vale destacar a importância do recorte de classe feito no estudo, pois são notáveis as diferenças microclimáticas no clima inter-urbano, como reflexo da segregação socioespacial e padrão de urbanização que se configura na cidade, com tipos distintos de materiais construtivos, por conta do poder aquisitivo da populaçáo, marcada por forte desigualdade socioespacial, deixando marcas na paisagem urbana.

O estudo do clima urbano com o paradigma da Geografia do Clima, lançado por Sant'Anna Neto, nos abre possibilidades mais interessantes e complexas, podendo estabelecer interfaces na análise geográfica do clima, como as relaçóes entre a Climatologia Geográfica e a Geografia Urbana, que traz uma dimensão de análise crítica do espaço, elemento importante para entendermos questôes estruturais, além das formas e processos, que estão relacionadas com a primeira. Sendo o espaço uma categoria de análise da ciência geográfica, cabe a nós nos debruçarmos mais sobre ele, sobretudo nos estudos do clima, pois os efeitos do tempo e clima têm uma dimensáo espacial, suas repercussóes são sentidas nas áreas urbanas de formas distintas. 


\section{REFERÊNCIAS BIBLIOGRÁFICAS}

ALVES, G. da A. O uso do centro da cidade de São Paulo e sua possibilidade de apropriação. São Paulo: Eletrônica GESP-LABUR, FFLCH, 2010.

ARMOND, N. B. Entre eventos e episódios: as excepcionalidades das chuvas e os alagamentos no espaço urbano do Rio de Janeiro. Dissertação (Mestrado em Geografia). Faculdade de Ciências e Tecnologia, Universidade Estadual Paulista,Presidente Prudente, 2014.

AZEVEDO, Aroldo. Subúrbios orientais de São Paulo. Tese.(Concurso à cátedra de Geografia do Brasil), Faculdade de Filosofia, Universidade de São Paulo, São Paulo, 1945.

BOMTEMPI, S. O bairro de São Miguel Paulista. São Paulo: Departamento de Cultura da Prefeitura Municipal, 1970.

CARLOS, A. F. A. O espaço urbano: novos escritos sobre a cidade. São Paulo: Eletrônica GESP-LABUR, FFLCH Edições, 2007.

A cidade. São Paulo: Contexto, 2013.

CRUZ, R. de C. A. da. Dimensão social da questão ambiental: contribuiçôes da obra do Prof. Milton Santos à compreensão do espaço geográfico. Revista GEOUSP, São Paulo, n. 3, pp. 09-12, 1998.

DAMIANI, A. L. A Cidade (Des)Ordenada. Boletim Paulista de Geografia, São Paulo, v. 72, pp. 95-109, 1994.

KOWARICK, L. Aa lutas sociais e a cidade - São Paulo: passado e presente. In: FONTES, P. (Org.).. Um nordeste em São Paulo: trabalhadores migrantes em São Miguel Paulista (1945-1966). Rio de Janeiro: FGV, 2008.

LANGENBUCH, J. R. A estruturação da grande São Paulo: estudo de geografia urbana. Rio de Janeiro, IBGE, 1971.

LOPES, R. H.Face Leste: revisitando a cidade. São Paulo: Mitra Diocesana, 2011.

MONTEIRO, C. A. de F. A cidade como processo derivador ambiental e a geração de um clima urbano - estratégias e abordagens geográficas. Revista GEOSUL. Florianópolis, ano 5, n. 9, pp. 80-114, Jan/Jun, 1990.

PAIVA, O. da C. Caminhos cruzados: migração e construção do Brasil moderno (19301950). Bauru: EdUSC (SP), 2004.

SANT'ANNA NETO, J. L. Clima e Organização do Espaço. Boletim de Geografia, Maringá (PR), v. 15, n.1, pp. 119-131, 1998.

. Por uma Geografia do Clima Antecedentes históricos, paradigmas contemporâneos e uma nova razão para um novo conhecimento. Terra Livre, São Paulo, v. 17, pp. 49-62, 2001.

Da climatologia geográfica à geografia do clima: gênese, paradigmas e aplicaçóes clima como fenômeno geográfico. Revista da ANPEGE, v. 4, pp. 1-18, 2008. 
. O clima urbano como construção social: da vulnerabilidade polissêmica das cidades enfermas ao sofisma utópico das cidades saudáveis. Revista Brasileira de Climatologia (online), v. 8, pp. 45-60, 2011.

SEABRA, O. de L. S. Territórios do uso: cotidiano e modo de vida. Revista Cidades, Presidente Prudente (SP), v. 1, n. 2, 2004, pp. 181-206.

Recebido para publicação em Agosto de 2017 Aceito para publicação em Dezembro de 2017 